a]-legòric. Aquest darrer sentit és el que vehicula les doctrines més profundes. Donaré tres exemples de tractament anagogic en l'obra de Sales.

El primer és la interpretació del mot geomètric (en sentit literal) diámetros com a portador d'un significat més alt, el de «potència generadora», per mitjà de l'expedient linguístic de llegir dia-metrós i interpretar «a través de la mesura». D'aquesta manera, el famós episodi de l'esclau en el Menó esdevé una profunda lliçó platònica sobre el Límit i l'il-limitat (pp. 90-91).

El segon exemple versa sobre l'inici de la República. Reprodueixo les mateixes paraules de l'autor: "Ahir vaig baixar (katében) al Pireu amb Glauc6” (327 a 1), així comença la República. S'ha indicat, doncs, que l'acció del diàleg és tota ella un descens o una baixada, una katábasis» (p. 143).

El tercer exemple és l'explotació hermenèutica de l'absència d'un quart interlocutor en el Timeu. Sales conclou: «La situació del Timeu i del Crities en el conjunt de l'obra platònica serà ben distinta segons considerem "verídica" o "irònica" aquesta identificació dels substituts del quart absent amb l'ideal del filòsof-rei» (p. 179).

És indubtable que en els diàlegs de Plató apareixen expressions metafòriques, simbòliques, anagògiques i àdhuc simples jocs de paraules. És probable que Plató jugui amb la tipologia d'alguns personatges. Aleshores, una de les tasques de l'estudiós és dilucidar aquests dobles o triples sentits, l'accés als quals exigeix uns coneixements filològics $\mathrm{i}$ històrics que no són a l'abast del lector corrent. Els intèrprets i els traductors solen senyalar aquestes circumstàncies en notes 0 complements informatius.

Una altra cosa molt diferent és basar sistemàticament la interpretació en significacions que no són òbvies en el text, tal com fa l'exègesi de caràcter anagògic. El primer inconvenient d'aquesta mena de procediments és que les seves proposicions no són falsables, $i$, com és ben sabut, amb proposicions d'aquesta mena no es poden construir sistemes científics. El segon inconvenient és que l'ús sistemàtic de l'anagogia remet a una criteriologia molt compromesa. En el cas dels textos bíblics, els criteris de l'exègesi al-legòrica poden ser dos: el magisteri autoritzat o el coneixement superior reservat a una minoria (gnosi). Posat que en l'estudi de Plató, cl magisteri autoritzat no és criteri atendible, resta l'opció del coneixement superior. L'atribució persistent de sentits no obvis al text platònic només cs pot fer des d'una pretensió de coneixement superior, global i sistemàtic del pensament del fildsof. Aquesta ciència platònica per a iniciats no és expossada enlloc en l'escrit de Sales, però la seva eficacitat es fa perceptible d'una punta a l'altra del llibre. L'autor, com el mateix Plato, disposa de timiótera que no transvasa al text escrit, almenys per ara. Nogensmenys, l'innegable interès de les interpretacions de Sales porten a desitjar que el proper lliurament presenti quelcom de semblant als agrapha dógmata platònics, j que d'aquesta manera el segon volum ofereixi, després d'un estètic enjòlit, la clau del primer.

Josep Montserrat

JOSEP M. COLL, Filosofía de la relación interpersonal, Barcelona: Facultat de Teología de Catalunya/PPU, 1990, 2 tomos, XVII $+\mathrm{XX}+771 \mathrm{pp}$.

Hay un género de libro que por su desmesura uno no puede dejar de admirar, aunque pocas veces constituya obra ejemplar. Se trata de los libros-río, esas obras imponentes, vastas y muy complejas que encontramos en todos los géneros literarios: desde las novelas-río a las memoriasrío pasando por los tratados fílosóficos-río. Josep M. Coll ba escrito uno de estos últimos tratados, en su origen una tesis doctoral, en el que su autor ha volcado todo su saber en torno a aquello que más hondamente le preocupa, a saber: el milagro y misterio de la intersubjetividad. Para em- 
pezar, pues, hay que felicitar al autor por su esfuerzo monumental y por su habilidad para organizar tal cantidad de material de modo que el lector no se sienta perdido en un laberinto de pasiones filosóficas y teologicas.

La filosofía postkantiana, sobre todo, claro es, la filosofía práctica y social, se halla polarizada por la poderosa tensión entre dos grandes corrientes que atraviesan obras, atutores, escuelas, corrientes y al conjunto mismo de la reflexión filosofica en todos sus géneros literarios: de un lado la tendencia al descentramiento del sujeto surgido de la filosofía moderna como filosoffa de la consciencia y que alcanzó sa apoteosis en la Ilustración; de otro, la exigencia de salvación del individuo frente a toda opresion, alienación, heteronomía, inautenticidad y falsa consciencia. El descentramiento histórico social del sujeto por parte del marxismo, el descentramiento psicoanálítico de Freud a Lacan, el descentramiento ontológico del primer Heidegger o el descentramiento linguiistico de ja filosofía analítica, el neoestructuralismo y la hermenéutica han coincidido en descubrir Ia fragilidad deI sujeto moderno, su condición socialmente derivada, y hasta denunciarlo como una ilusion. Sin ęmbargo, casi ningún pensador moderno ha renunciado enteramente a alguna versión de la idea de individuo autoconsciente, crítico, autónomo y capaz de autorrealizarse.

Puede decirse que la investigacion de J.M. Coll se realiza claramente en este horizonte. Pero el punto de partida filosófico desde el que Coll aborda su empresa de un esclarecimiento de la intersubjetividad está constituido por el marco conceptual del personalismo para el cual «el punto de partida y la meta de la reflexión es la comunicación fraterna o el amor que crea comunion, un amor que se confiesa como divino, derramado por el espíritu de Dios en nuestros corazones, precisamente para poder ser radicalmente humanos (p. 729). Este punto de partida, que es también la meta a la que se llega/regresa continuamente a lo largo de la obra, distingue a ésta de la mayoría de las investigaciones actuales porque persigue la reconciliación de la filosofia con la teología desde el supuesto de que no hay razón șin fe.

La obra de Coll se despliega en tres grandes etapas. Las dos primeras se contienen en el primer tomo, y la tercera en el segundo. Una primera etapa es la temática, en la que encontramos una exposición global del personalismo realizada desde un punto de vista más bien fenomenologico, que persigue la descripción de la relación personalista auténtica, es decir, aquella en la que dominan la palabra, el amor (fidelidad confianza, simpatía, respeto) y la comunión interpersonal sobre el individualismo, el pecado, etc. En esta parte se examina la dimensión personal de las cosas de tal modo que la reflexión se abre continuamente a la religión y a lo $\mathrm{Ab}$ soluto.

La segunda etapa tiene un carácter marcadamente metodológico, y es, en mi opinión, la menos convincente del trabajo, pues pretende dotar de mayor rigor a la concepción personalista recurriendo a Fichte y Husserl, dos campeones de la filosofía del yo sin atributos. Coll persigue complementar la intuición dialógica personalista con un planteamiento trascendental que cristaliza en una síntesis, que constituye el centro de gravedad argumentativo de todo el libro (pp. 213 . 218)

La tercera y última etapa, y también la más extensa y sin duda más lograda de] conjunto, consiste en una "verificación» del modelo elaborado, mediante una confrontación con otro paradigma, el sartriano, en la que, por descontado, Sartre sale más bien mal parado de la prueba. Esta lectura interesada de la obra de Sartre, especialmente de sus dos obras capitales -El ser y la nada y La crítica de la razón dialéctica, incluida su segundo volumen publicado póstumamente-, resulta en un muy interesante examen crítico del problema del otro en dicho autor. Las deficiencias que Coll señala en el pensa- 
miento sartriano sobre la intersubjetividad son muy reales y logra sistematizarlas de modo muy coherente. La solución propuesta, como el personalismo mismo, claro, ya no puede pretender una aceptación racional por parte de cualquier lector, sino mas bien una forma de adhesion. Aunque en estos tiempos en los que las fuentes de la solidaridad manan cada vez con mayor dificultad, la investigación de Coll da testimonio de un compromiso ético con el que, más allá de sus dimensiones teológicas y religiosas, es difícil no estar de acuerdo, y que la filosofía debe esforzarse por iluminar.

\section{Gerard Vilar}

\section{F. BÁrCena ORBe et al., La filosofía de la educación en Europa, Madrid: Dykinson, 1992.}

Hasta hace relativamente pocos años, la filosofía de la educación no había encontrado su lugar en el ámbito filosófico y pedagógico en nuestro país. Frente a otras ramas de la filosofía, tales como la filosofía de la ciencia, del derecho, del arte, de la moral, de la historia, de la política o de la religión, que eran incuestionables, la filosofía de la educación aparecía como poco apreciada tanto por filósofos como por pedagogos. Unos la consideraban como poco filosofica, los otros excesivamente. Tal situación contrastaba con la realidad europea, en la que la filosofía de la educación goza de gran prestigio universitario. Pero por suerte la situación ha cambiado.

Hoy, la filosofía de la educación se ha convertido en una asignatura obligatoria (u optativa) en la mayoría de los planes de estudio de nuestras facultades de ciencias de la cducación o de pedagogía. El libro que presentamos tiene como objetivo primordial mostrar la fecunda actividad filosóficoeducativa en nuestro entorno, y contextualizarla en el ámbito europeo más reciente, concretamente en países como Alemania, Italia y el Reino Unido.
Probablemente el lector poco introducido en esta disciplina se pregunte la razón de la ausencia, por ejemplo, de Francia. La respuesta que los autores de este trabajo nos ofrecen está clata: si exceptuamos al recientemente desaparecido profesor Olivier Reboul —catedrático de filosofía de la educación en Strasbourg - no descubrimos filosofía de la educación alguna en nuestro país vecino.

El panorama europeo acerca de la más actual filosofía de la educación que los autores de este libro nos ofrecen es, a mi juicio, acertado y bien elaborado. En primer lugar encontramos una presentación general del professor José Antonio Ibáñez-Martín -catedrático de la Universidad Complutense de Madrid- sobre el tema: «La filosofía de la educación y el futuro de Europan. A continuación, el resto de los capitulos, todos ellos elaborados por profesores de la misma Universidad Complutense, posee idéntica estructura: una introducción general al ámbito filosofico-educativo estudiado, y una selección de textos (artículos) de algunos filósofos, representativos en su ámbito cultural.

El apartado sobre la filosofía de la educación en España se complementa con una extensa bibliografía, que vicne a corroborar lo que ya mostramos al principio: la excelente salud de la que goza este campo de investigación en el conjunto de nuestras comunidades autónomas. El capítulo se completa con tres textos de otros tantos autores, todos ellos de reconocido prestigio en círculos académicos: Francisco Altarejos (Universidad de Navara), Juan Escámez (Universidad de Valencia) y Octavi Fullat (Universitat Autònoma de Barcelona).

En definitiva, celebramos la aparición de un material de gran valor, no solamente para introducirse en la actualióad europea de la filosofía de la educación, sino también a título de selección de importantes artículos difíciles de encontrar ante la gran cantidad de éstos que se publican en revistas especializadas.

Joan-Carles Melich 